\title{
Heart Failure Drug Modifies the Intrinsic Dynamics of the Pre- Power Stroke State of Cardiac Myosin
}

Shaima Hashem, ${ }^{\mathrm{a} \dagger}$ William George Davies $^{\mathrm{a}}$ and Arianna Fornili ${ }^{\mathrm{a}, \mathrm{b}^{\star}}$

\footnotetext{
School of Biological and Chemical Sciences, Queen Mary University of London, London, E1 4NS, United Kingdom

. The Thomas Young Centre for Theory and Simulation of Materials, London, WC1E 6BN, United Kingdom

+ Present address: Department of Chemistry, University of Pisa, Via Giuseppe Moruzzi 13, 56124 Pisa, Italy

*corresponding author, email: a.fornili@qmul.ac.uk
}

\section{Supplementary Information}

Table S1. Residues within $4 \AA$ of OM functional groups in the PPS and NR states.

\begin{tabular}{|c|c|c|}
\hline OM functional group & PPS $^{\mathbf{a}}$ & $\mathbf{N R}^{\mathbf{a}}$ \\
\hline \multirow{4}{*}{$\begin{array}{c}\text { Carboxymethyl- } \\
\text { piperazine (a) }\end{array}$} & K146, R147, S148, N160, Q163, Y164 & M90, A91, L96, V101, S118, G119, L120 \\
\hline & & M493 \\
\hline & & I702, C705 \\
\hline & N711, R721, A767, L770, Y722, G771, E774 & P710 \\
\hline \multirow{2}{*}{ Fluoro-benzyl (b) } & T167, Y164, D168 & A91, G119, L120 \\
\hline & I713, N711, R712, L770 & N711, P710, R712 \\
\hline \multirow{2}{*}{ Amino-carbamoyl (c) } & Y164, D168 & A91, M92 \\
\hline & N711, R712 & R712 \\
\hline \multirow{4}{*}{ Methylpyridin-3-yl (d) } & D168, Y164 & A91, M92, F84 \\
\hline & $\mathrm{H} 492$ & \\
\hline & H666 & \\
\hline & P710, N711, R712, K762 & N711, R712, I713, L770 \\
\hline
\end{tabular}

aThe residues were determined on representative structures extracted from MD simulations of the motor domain in the OM-bound PPS and NR state. Representative structures were determined through cluster analysis of the concatenated trajectories of each state (see Methods). Residues are coloured according to their sub-domain (see Figure 1 legend). Residues common to the PPS and NR pockets are highlighted in bold. 
Table S2. Cluster analysis of OM-bound simulations.

\begin{tabular}{ccccccc} 
\# cluster & $\begin{array}{c}\text { population }^{\mathbf{a}} \\
(\mathbf{\%})\end{array}$ & $\begin{array}{c}\text { RMSD }^{\mathbf{b}} \\
(\mathbf{A})\end{array}$ & $\begin{array}{c}\text { MD1 }^{\mathbf{c}} \\
\mathbf{( \% )}\end{array}$ & $\begin{array}{c}\text { MD2 }^{\mathbf{c}} \\
\mathbf{( \% )}\end{array}$ & $\begin{array}{c}\text { MD3 }^{\mathbf{c}} \\
(\mathbf{\%})\end{array}$ & $\begin{array}{c}\text { MD4 }^{\mathbf{c}} \\
\mathbf{( \% )}\end{array}$ \\
\hline 1 & 87.8 & 1.5 & 24.4 & 19.0 & 23.3 & 21.1 \\
2 & 7.9 & 2.9 & 0.6 & 5.3 & 0.0 & 2.1 \\
3 & 2.2 & 1.7 & 0.0 & 0.0 & 1.6 & 0.5 \\
4 & 0.7 & 2.7 & 0.0 & 0.0 & 0.0 & 0.7
\end{tabular}

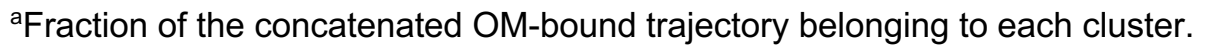

${ }^{\mathrm{b}} \mathrm{RMSD}$ from the OM X-ray structure non-hydrogen atoms. The fitting of the structures was performed using all the $\mathrm{C}^{\alpha}$ atoms in the protein.

${ }^{\mathrm{C}}$ Contribution to the cluster population from each OM-bound simulation. 
Table S3. Frequency of occurrence (occupancy) of OM-myosin hydrogen bonds during OMbound PPS and NR simulations

\begin{tabular}{|c|c|c|c|c|c|c|c|c|c|c|c|}
\hline \multicolumn{6}{|c|}{ PPS $^{a}$} & \multicolumn{6}{|c|}{$N R^{a, b}$} \\
\hline Residc $^{c}$ & MD1 & MD2 & MD3 & MD4 & Average & Resid $^{c}$ & OMA1 & OMA2 & OMB1 & OMB2 & Average \\
\hline N711 & 0.83 & 0.58 & 0.81 & 0.68 & 0.72 & R712 & 0.18 & 0.47 & 0.61 & 0.31 & 0.39 \\
\hline D168 & 0.71 & 0.58 & 0.82 & 0.30 & 0.60 & C705 & 0.04 & 0.50 & 0.02 & 0.47 & 0.25 \\
\hline $\mathrm{R} 712$ & 0.54 & 0.60 & 0.50 & 0.45 & 0.52 & A91 & 0.11 & 0.22 & 0.25 & 0.15 & 0.18 \\
\hline $\mathrm{R} 147$ & 0.07 & 0.13 & 0.00 & 0.19 & 0.10 & N711 & 0.09 & 0.22 & 0.22 & 0.00 & 0.14 \\
\hline Q163 & 0.01 & 0.18 & 0.01 & 0.05 & 0.06 & S118 & 0.06 & 0.12 & 0.00 & 0.10 & 0.07 \\
\hline N160 & 0.00 & 0.03 & 0.18 & 0.00 & 0.05 & K762 & 0.21 & 0.00 & 0.01 & 0.01 & 0.06 \\
\hline
\end{tabular}

aHydrogen bonds calculated with VMD on snapshots sampled every 100 ps using a threshold of $3.5 \AA$ on the $\mathrm{D}$ (onor)-A(cceptor) distance and $30^{\circ}$ on the $\mathrm{D}-\mathrm{H}-\mathrm{A}$ angle. Only residues with frequency $>0.1$ in at least one replica are reported.

${ }^{b} \mathrm{NR}$ values are taken from Ref. 10 in the main text and reported here for ease of comparison.

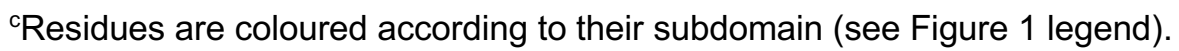


Table S4. Frequency of occurrence (occupancy) of OM-myosin contacts during OM-bound PPS and NR simulations.

\begin{tabular}{|c|c|c|c|c|c|c|c|c|c|c|c|}
\hline \multicolumn{7}{|c|}{ PPS $^{a}$} & \multicolumn{5}{|c|}{$N R^{a, b}$} \\
\hline Resid $^{c}$ & OM1 & OM2 & OM3 & OM4 & Average & Resid & OMA1 & OMA2 & OMB1 & OMB2 & Average \\
\hline Y164 & $1.00(1.00)$ & $1.00(1.00)$ & $1.00(1.00)$ & $1.00(1.00)$ & $1.00(1.00)$ & A91 & $0.96(0.84)$ & $1.00(0.97)$ & $1.00(0.96)$ & $1.00(0.93)$ & $0.99(0.93)$ \\
\hline R712 & $1.00(0.99)$ & $1.00(0.96)$ & $1.00(0.99)$ & $0.97(0.86)$ & $0.99(0.95)$ & $\mathrm{R} 712$ & $0.94(0.93)$ & $1.00(0.99)$ & $1.00(1.00)$ & $1.00(1.00)$ & $0.99(0.98)$ \\
\hline L770 & $0.97(0.97)$ & $0.91(0.87)$ & $0.96(0.96)$ & $0.97(0.97)$ & $0.95(0.94)$ & P710 & $0.90(0.10)$ & $1.00(0.15)$ & $1.00(0.36)$ & $1.00(0.15)$ & $0.97(0.19)$ \\
\hline N711 & $1.00(1.00)$ & $0.90(0.78)$ & $1.00(1.00)$ & $0.90(0.89)$ & $0.95(0.92)$ & $\mathrm{S} 118$ & $0.99(0.57)$ & $0.97(0.85)$ & $0.88(0.72)$ & $0.96(0.85)$ & $0.95(0.75)$ \\
\hline T167 & $0.98(0.98)$ & $0.94(0.94)$ & $0.97(0.97)$ & $0.88(0.88)$ & $0.94(0.94)$ & M92 & $0.83(0.60)$ & $1.00(0.93)$ & $0.98(0.85)$ & $1.00(0.94)$ & $0.95(0.83)$ \\
\hline H666 & $0.97(0.97)$ & $0.88(0.88)$ & $0.95(0.95)$ & $0.95(0.95)$ & $0.94(0.94)$ & C705 & $0.94(0.94)$ & $0.96(0.96)$ & $0.87(0.77)$ & $1.00(1.00)$ & $0.94(0.92)$ \\
\hline P710 & $0.97(0.00)$ & $0.88(0.00)$ & $0.93(0.01)$ & $0.82(0.00)$ & $0.90(0.00)$ & 1702 & $0.71(0.63)$ & $0.91(0.91)$ & $0.96(0.82)$ & $0.97(0.97)$ & $0.89(0.83)$ \\
\hline N160 & $0.94(0.94)$ & $0.69(0.68)$ & $0.94(0.94)$ & $0.88(0.88)$ & $0.86(0.86)$ & L96 & $0.70(0.70)$ & $0.86(0.86)$ & $0.80(0.80)$ & $0.83(0.83)$ & $0.80(0.80)$ \\
\hline Q163 & $0.94(0.91)$ & $0.84(0.82)$ & $0.78(0.74)$ & $0.76(0.71)$ & $0.83(0.79)$ & N711 & $0.28(0.22)$ & $0.96(0.85)$ & $0.99(0.48)$ & $0.95(0.50)$ & $0.80(0.51)$ \\
\hline 1713 & $0.71(0.71)$ & $0.84(0.84)$ & $0.74(0.74)$ & $0.82(0.82)$ & $0.77(0.77)$ & M90 & $0.50(0.50)$ & $0.97(0.68)$ & $0.55(0.50)$ & $0.99(0.92)$ & $0.75(0.65)$ \\
\hline E774 & $0.89(0.89)$ & $0.47(0.47)$ & $0.87(0.87)$ & $0.83(0.83)$ & $0.76(0.76)$ & G701 & $0.52(0.00)$ & $0.61(0.00)$ & $0.97(0.00)$ & $0.47(0.00)$ & $0.64(0.00)$ \\
\hline Y722 & $0.73(0.73)$ & $0.56(0.56)$ & $0.81(0.81)$ & $0.81(0.81)$ & $0.72(0.72)$ & M493 & $0.54(0.54)$ & $0.62(0.62)$ & $0.59(0.59)$ & $0.60(0.60)$ & $0.59(0.59)$ \\
\hline R147 & $0.94(0.93)$ & $0.84(0.82)$ & $0.05(0.05)$ & $0.97(0.97)$ & $0.70(0.69)$ & G119 & $0.89(0.00)$ & $0.60(0.00)$ & $0.35(0.00)$ & $0.33(0.00)$ & $0.54(0.00)$ \\
\hline D168 & $0.74(0.74)$ & $0.60(0.60)$ & $0.88(0.88)$ & $0.35(0.35)$ & $0.64(0.64)$ & L93 & $0.16(0.00)$ & $0.52(0.00)$ & $0.60(0.00)$ & $0.81(0.01)$ & $0.52(0.00)$ \\
\hline K146 & $0.89(0.89)$ & $0.26(0.24)$ & $0.86(0.86)$ & $0.21(0.21)$ & $0.56(0.55)$ & T94 & $0.15(0.11)$ & $0.56(0.51)$ & $0.60(0.43)$ & $0.75(0.67)$ & $0.51(0.43)$ \\
\hline R721 & $0.57(0.57)$ & $0.44(0.44)$ & $0.49(0.49)$ & $0.50(0.50)$ & $0.50(0.50)$ & L770 & $0.15(0.15)$ & $0.59(0.59)$ & $0.47(0.47)$ & $0.48(0.48)$ & $0.42(0.42)$ \\
\hline G771 & $0.45(0.00)$ & $0.55(0.00)$ & $0.19(0.00)$ & $0.61(0.00)$ & $0.45(0.00)$ & E497 & $0.13(0.13)$ & $0.30(0.30)$ & $0.67(0.67)$ & $0.50(0.50)$ & $0.40(0.40)$ \\
\hline $\mathrm{S} 148$ & $0.78(0.76)$ & $0.06(0.05)$ & $0.00(0.00)$ & $0.86(0.76)$ & $0.42(0.40)$ & V698 & $0.90(0.26)$ & $0.01(0.00)$ & $0.51(0.24)$ & $0.05(0.01)$ & $0.37(0.13)$ \\
\hline L120 & $0.46(0.46)$ & $0.56(0.56)$ & $0.06(0.06)$ & $0.59(0.57)$ & $0.42(0.41)$ & $\mathrm{F} 121$ & $0.28(0.28)$ & $0.00(0.00)$ & $0.81(0.81)$ & $0.32(0.32)$ & $0.35(0.35)$ \\
\hline E497 & $0.18(0.18)$ & $0.12(0.12)$ & $0.64(0.64)$ & $0.08(0.08)$ & $0.26(0.26)$ & F84 & $0.17(0.17)$ & $0.08(0.08)$ & $0.25(0.25)$ & $0.60(0.60)$ & $0.27(0.27)$ \\
\hline $\mathrm{H} 492$ & $0.04(0.04)$ & $0.08(0.08)$ & $0.45(0.45)$ & $0.05(0.05)$ & $0.16(0.16)$ & 1713 & $0.10(0.09)$ & $0.77(0.77)$ & $0.09(0.09)$ & $0.13(0.13)$ & $0.27(0.27)$ \\
\hline A767 & $0.47(0.05)$ & $0.00(0.00)$ & $0.12(0.01)$ & $0.00(0.00)$ & $0.15(0.01)$ & V101 & $0.00(0.00)$ & $0.16(0.16)$ & $0.08(0.08)$ & $0.39(0.39)$ & $0.16(0.16)$ \\
\hline E500 & $0.11(0.11)$ & $0.13(0.13)$ & $0.10(0.10)$ & $0.09(0.09)$ & $0.11(0.11)$ & L120 & $0.39(0.30)$ & $0.04(0.03)$ & $0.07(0.07)$ & $0.05(0.04)$ & $0.14(0.11)$ \\
\hline & & & & & & K762 & $0.36(0.36)$ & $0.03(0.03)$ & $0.02(0.02)$ & $0.03(0.03)$ & $0.11(0.11)$ \\
\hline & & & & & & E500 & $0.08(0.08)$ & $0.01(0.01)$ & $0.21(0.21)$ & $0.04(0.04)$ & $0.08(0.08)$ \\
\hline & & & & & & F489 & $0.13(0.13)$ & $0.00(0.00)$ & $0.00(0.00)$ & $0.00(0.00)$ & $0.03(0.03)$ \\
\hline
\end{tabular}

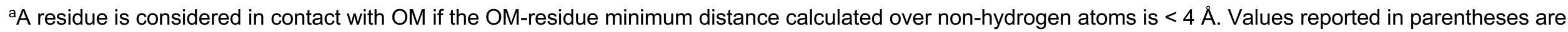
calculated considering only the atoms in the side chains. Only residues with frequency $>=0.1$ in at least one replica are reported.

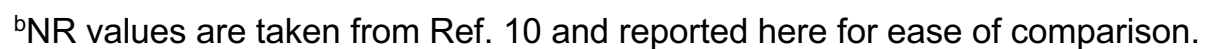

${ }^{\mathrm{c}}$ Residues are coloured according to their sub-domain (see Figure 1 legend). 
Table S5 - Average frequency of occurrence (occupancy) of hydrogen bonds near the OM binding site (AvgHB).

\begin{tabular}{ccccc} 
HB $^{\mathbf{a}}$ & PPS Apo & $\begin{array}{c}\text { PPS OM-bound } \\
\text { Intra N-term }\end{array}$ & NR Apo & NR OM-bound \\
\hline R17-S148 & 0.00 & $\begin{array}{c}0.46 \\
\text { Intra RH }\end{array}$ & 0.00 & 0.00 \\
\hline E497-Y501 & 0.49 & 0.91 & 0.76 & 0.84 \\
E499_K503 & 0.33 & $\begin{array}{c}0.81 \\
\text { Intra SH1 }\end{array}$ & 0.00 & 0.00 \\
\hline R671-N696 & 0.00 & 0.00 & 0.34 & 0.84 \\
I704-G708 & 0.45 & 0.89 & 0.34 & 0.10 \\
I704-K707 & 0.00 & 0.00 & 0.14 & 0.54 \\
& & & & \\
\hline L714-F718 & 0.69 & 0.95 & 0.46 & 0.95 \\
Y715-T761 & 0.33 & 0.78 & 0.00 & 0.00 \\
& & N-term/CLD & & 0.57 \\
\hline T94-N711 & 0.00 & 0.00 & 0.10 & 0.00 \\
K146-D778 & 0.01 & 0.69 & 0.00 & 0.00 \\
R169-D717 & 0.21 & 0.83 & 0.00 & \\
\hline E500-K762 & 0.42 & RH/CLD & & 0.65 \\
E504-K762 & 0.27 & 0.60 & 0.00 \\
E504-T761 & 0.23 & 0.88 & 0.72 & \\
& & 1.00 & 0.00 & \\
\hline
\end{tabular}

anter-residue hydrogen bonds within $10 \AA$ of OM. Colour is used to highlight pairs where the HB frequency difference is largest in the PPS (blue) or the NR (red) state. Only pairs with $\mid \Delta$ HBFreq $\mid>0.4$ for at least one of the two states (PPS or NR) are shown. 
Table S6 - Activity and binding affinity data for OM and analogues.

\begin{tabular}{|c|c|c|c|c|c|c|c|c|c|c|}
\hline Compound $^{a}$ & $\begin{array}{c}\% \text { ATPase } \\
(\exp )^{\mathrm{b}}\end{array}$ & $\begin{array}{l}\% \text { ATPase } \\
\text { (predicted) }^{c}\end{array}$ & $\begin{array}{l}\text { Binding } \\
\text { affinity } \\
(N R)^{d}\end{array}$ & $\begin{array}{l}\text { Binding } \\
\text { affinity } \\
\text { (PPS) }^{d}\end{array}$ & $\begin{array}{c}\text { Average } \\
\text { Steric } \\
(\mathrm{NR})^{\mathrm{e}}\end{array}$ & $\begin{array}{l}\text { Average } \\
\text { Steric } \\
\text { (PPS) }^{\mathrm{e}}\end{array}$ & $\begin{array}{c}\text { Average } \\
\text { Hydrophobic } \\
\text { (NR) }^{\mathrm{e}}\end{array}$ & $\begin{array}{l}\text { Average } \\
\text { Hydrophobic } \\
\text { (PPS) }^{e}\end{array}$ & $\begin{array}{c}\text { Average } \\
\text { hydrogen } \\
\text { bond (NR) }\end{array}$ & $\begin{array}{c}\text { Average } \\
\text { hydrogen } \\
\text { bond (PPS) }\end{array}$ \\
\hline \multicolumn{11}{|l|}{ Group 1} \\
\hline $2 a$ & 10.3 & 18.0 & -7.2 & -8.0 & -5.3 & -5.5 & -1.1 & -1.7 & -0.5 & -0.7 \\
\hline $5 a$ & 1.6 & 21.3 & -6.8 & -7.5 & -5.0 & -5.2 & -1.1 & -1.8 & -0.3 & -0.5 \\
\hline $6 a$ & 11.9 & 13.5 & -6.8 & -7.7 & -5.0 & -5.4 & -1.3 & -1.8 & -0.3 & -0.3 \\
\hline $11 a$ & 20.3 & 10.9 & -7.0 & -7.7 & -5.3 & -5.4 & -0.9 & -1.6 & -0.3 & -0.5 \\
\hline \multicolumn{11}{|l|}{ Group 2} \\
\hline OM & 58.0 & 70.0 & -7.8 & -9.7 & -6.7 & -6.6 & -0.4 & -0.6 & -0.6 & -1.2 \\
\hline $1 a$ & 51.1 & 47.0 & -7.3 & -8.2 & -4.8 & -5.4 & -1.1 & -1.7 & -0.9 & -1.0 \\
\hline $9 a$ & 53.3 & 58.3 & -6.9 & -7.9 & -4.9 & -5.6 & -1.1 & -1.6 & -0.7 & -0.6 \\
\hline $15 b$ & 35.0 & 42.1 & -6.9 & -8.6 & -5.2 & -5.3 & -0.9 & -1.5 & -0.9 & -1.3 \\
\hline $21 a$ & 44.0 & 65.0 & -6.3 & -7.6 & -4.9 & -5.4 & -0.5 & -0.9 & -0.9 & -1.1 \\
\hline \multicolumn{11}{|l|}{ Group 3} \\
\hline $10 \mathrm{~b}$ & 122.4 & 85.2 & -7.5 & -8.5 & -5.4 & -5.6 & -0.8 & -1.0 & -0.9 & -1.4 \\
\hline $13 b$ & 91.6 & 119.4 & -7.2 & -8.5 & -5.4 & -6.1 & -0.8 & -1.0 & -0.6 & -1.0 \\
\hline $14 a$ & 81.4 & 60.4 & -6.6 & -7.7 & -4.9 & -5.6 & -0.8 & -1.2 & -0.7 & -0.7 \\
\hline $14 b$ & 95.1 & 65.0 & -6.8 & -8.5 & -5.1 & -5.6 & -0.9 & -1.5 & -0.7 & -1.0 \\
\hline
\end{tabular}

${ }^{a}$ Compounds are divided into three groups, with lower (group 1, light blue), similar (group 2, blue) or higher (group 3, orange) \% increase in ATPase activity (experimental data) compared to OM.

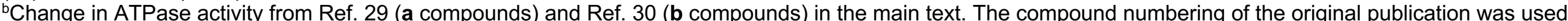

${ }^{\circ}$ Change in ATPase activity predicted from the linear regression model 1 (Table S7).

${ }^{\mathrm{d} B i n d i n g}$ affinity ( $\mathrm{kcal} / \mathrm{mol}$ ) predicted by AutoDock Vina (best binding pose).

eIndividual components (steric, hydrophobic and hydrogen-binding) of the binding affinity (kcal/mol), averaged over all the Vina binding poses. 
Table S7 - Linear models of \% increase in ATPase activity for OM and analogues.

$\begin{array}{cccccccccc}\text { Models }^{\mathbf{a}} & \begin{array}{c}\text { Adjusted R- } \\ \text { squared }\end{array} & \text { Intercept } & \begin{array}{c}\text { Intercept } \\ \mathbf{p}-\mathrm{value}\end{array} & \mathbf{c 1} & \begin{array}{c}\mathbf{c 1} \\ \mathbf{p}-\mathrm{value}\end{array} & \mathbf{c 2} & \begin{array}{c}\mathbf{c 2} \\ \mathbf{p}-\mathrm{value}\end{array} & \begin{array}{c}\mathbf{c 3} \\ \mathbf{c 3} \\ \mathbf{p - v a l u e}\end{array} \\ \mathbf{1} & 0.66 & 52.1 & 8.4 \mathrm{E}-04 & -27.2 & 1.7 \mathrm{E}-03 & -32.6 & 1.2 \mathrm{E}-03 & - & - \\ \mathbf{2} & 0.62 & 53.3 & 2.7 \mathrm{E}-03 & -28.6 & 1.5 \mathrm{E}-02 & -3.2 & 8.4 \mathrm{E}-01 & -35.4 & 4.1 \mathrm{E}-02 \\ \mathbf{3} & 0.35 & 67.4 & 5.2 \mathrm{E}-01 & -52.0 & 3.5 \mathrm{E}-01 & -126.6 & 5.2 \mathrm{E}-02 & - & - \\ \mathbf{4} & 0.32 & 194.2 & 4.4 \mathrm{E}-02 & -33.9 & 4.1 \mathrm{E}-01 & -223.0 & 2.4 \mathrm{E}-02 & - & - \\ \mathbf{5} & 0.11 & 36.1 & 1.0 \mathrm{E}-01 & -16.7 & 2.4 \mathrm{E}-01 & -11.6 & 2.0 \mathrm{E}-01 & - & -\end{array}$

aThe linear models Intercept $+c_{1} x_{1}+c_{2} x_{2}\left(+c_{3} x_{3}\right)$ were built-up using the following combinations of variables:

Model 1: $x_{1}=$ average steric score, $x_{2}=$ average HB score

Model 2: $x_{1}=$ average steric score, $x_{2}=$ average hydrophobic score, $x_{3}=$ average HB score

Model 3: $x_{1}=$ average steric score, $x_{2}=$ average HB score (PPS energy only)

Model 4: $x_{1}=$ average steric score, $x_{2}=$ average HB score (NR energy only)

Model 5: $x_{1}=$ steric score, $x_{2}=H B$ score (best binding pose only) 


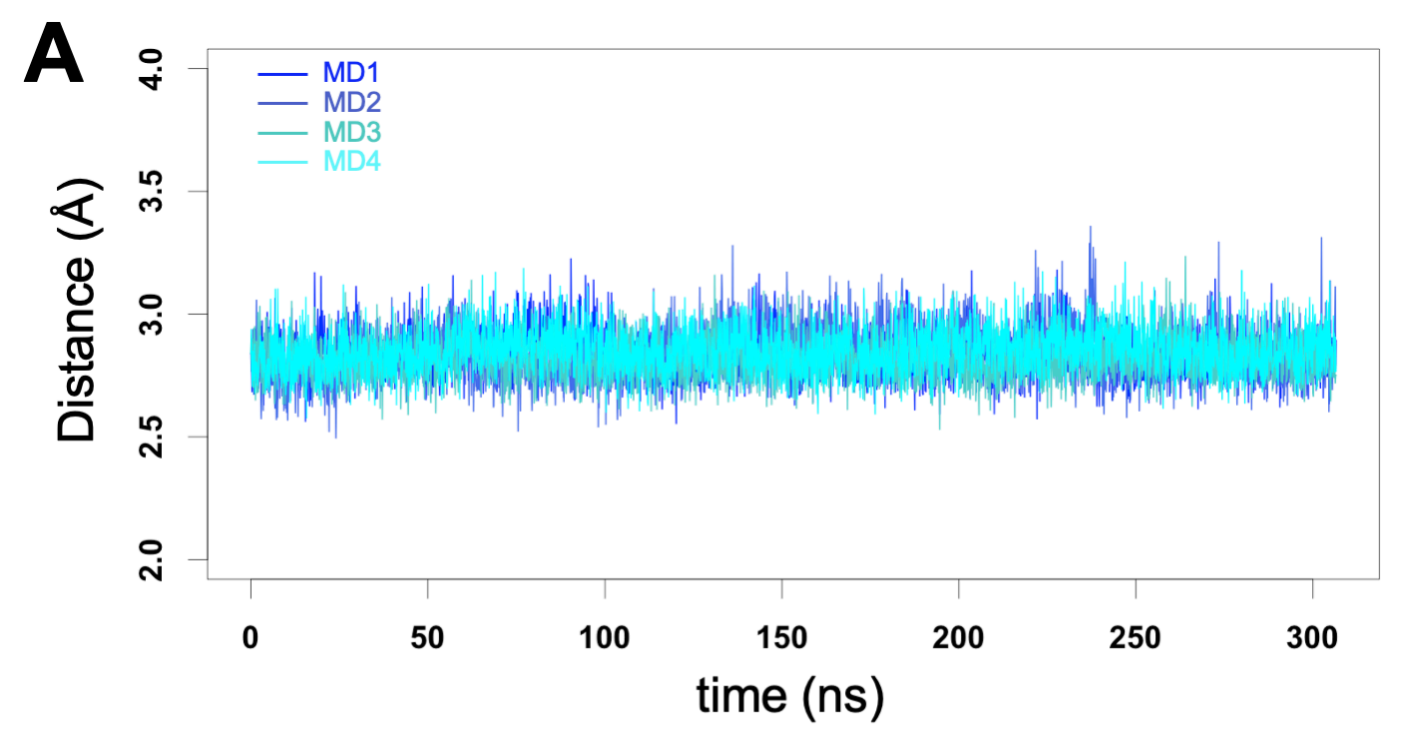

B

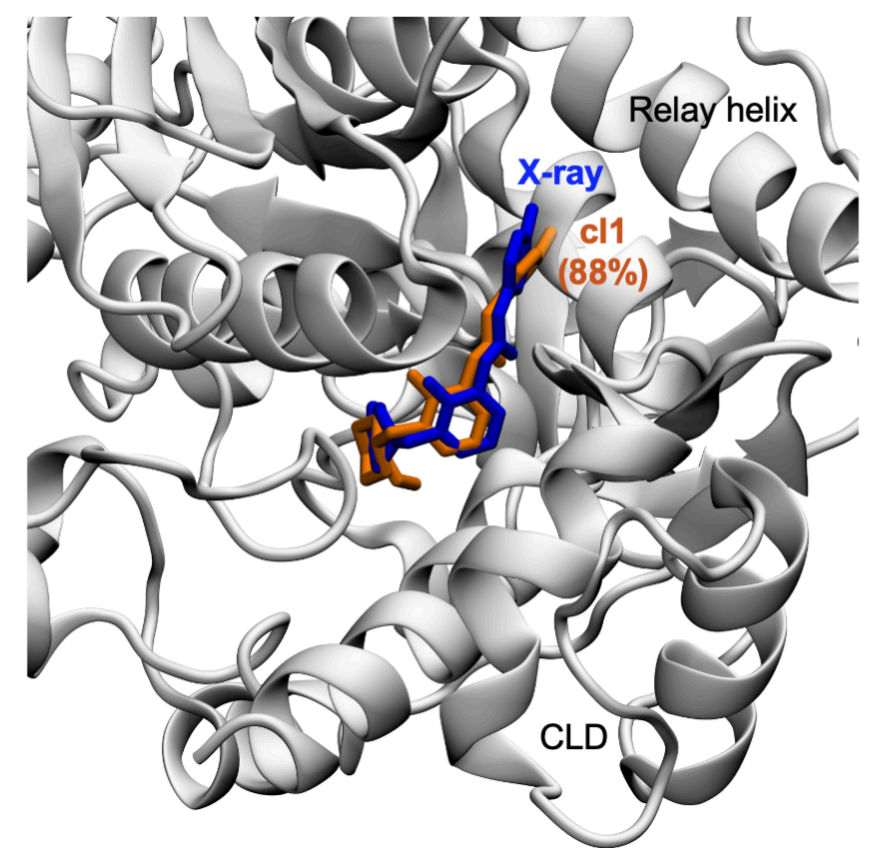

Figure S1. Stability of OM binding to myosin. A. Time evolution of the OM-protein distance for the PPS OM-bound simulations. The distance was calculated as the minimum value over all possible pairs of non-hydrogen atoms. B. Superimposition of the $\mathrm{X}$-ray (blue) and cluster 1 representative (orange) OM structure. The protein is shown as white cartoon. The overall cluster population is reported in parentheses. 


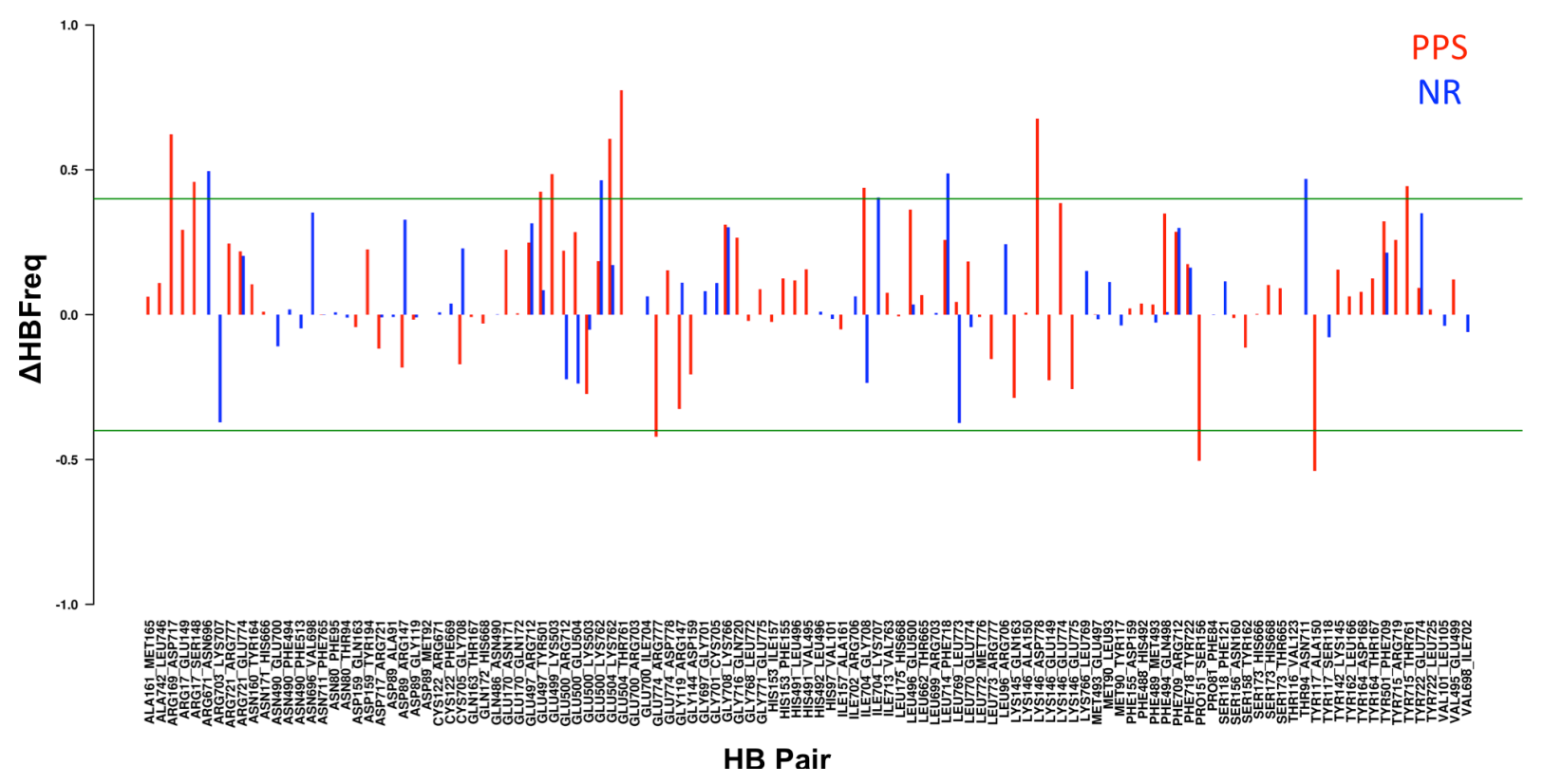

Figure S2. Difference in HB frequency of occurrence ( $\triangle \mathrm{HBfreq}$ ) of hydrogen bonds near the OM binding site. Only hydrogen bonds between residues within $10 \AA$ of OM are reported. Green lines indicate the -0.4 and 0.4 thresholds. 

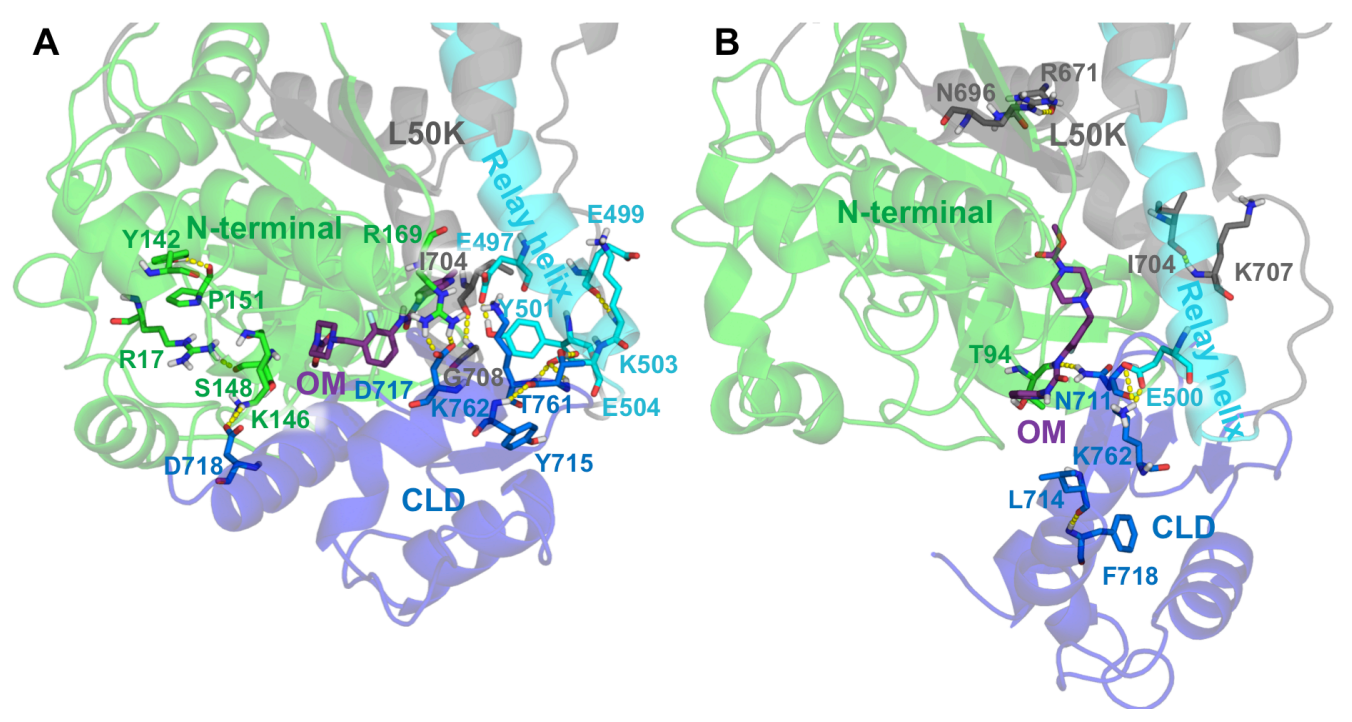

Figure S3. OM-stabilised hydrogen bonds near the OM binding site. Hydrogen bonds with $\triangle$ HBfreq $>0.4$ are indicated with yellow dashed lines on structures extracted from PPS (A) and NR (B) OM-bound simulations. 


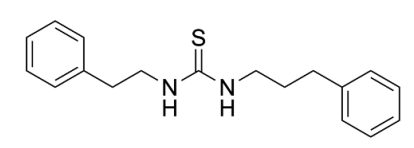

$2 a$

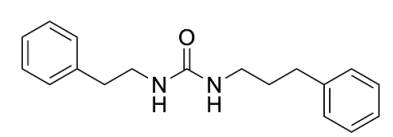

$1 \mathrm{a}$

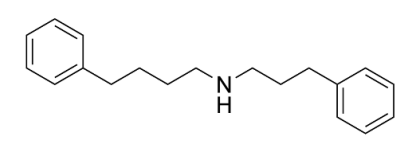

$6 \mathbf{a}$

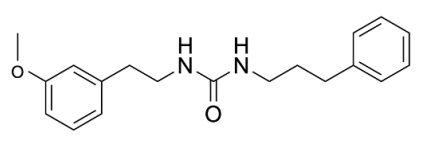

$15 b$<smiles>O=C(NCCCc1ccccc1)NC1CCCCC1</smiles>

$11 \mathrm{a}$<smiles>CN(C)S(=O)(=O)c1ccc(CCNC(=O)NCCCc2ccccc2)cc1</smiles>

$10 b$<smiles>O=C(NCCc1ccccc1)NCc1ccccc1</smiles>

$9 a$

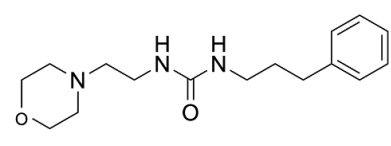

$21 a$

Figure S4. Chemical structures of OM analogues. The numbering of the compounds is the same as the one used in the original publication ( $a=$ Ref. $29, b=$ Ref. 30). 
Group 1

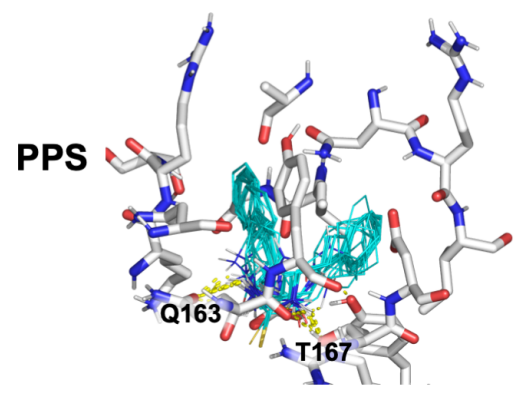

NR

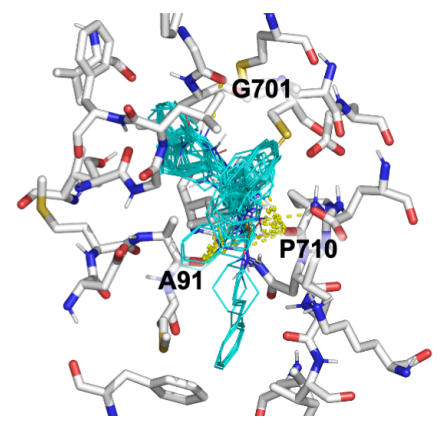

Group 2
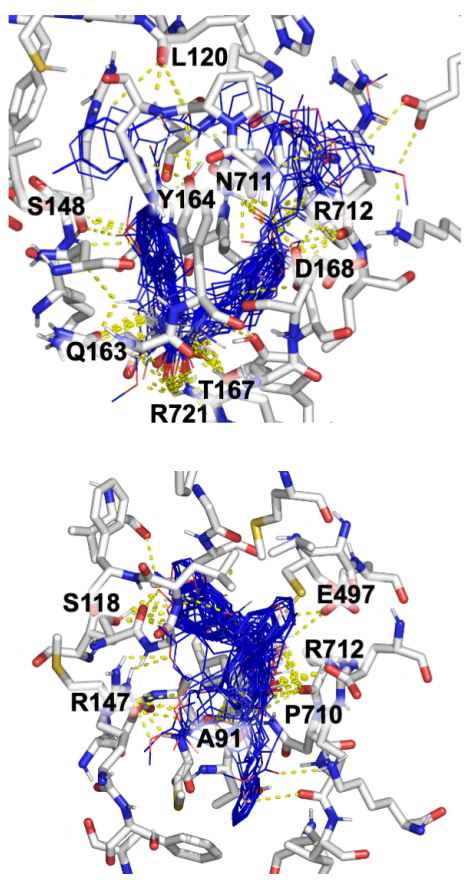

Group 3
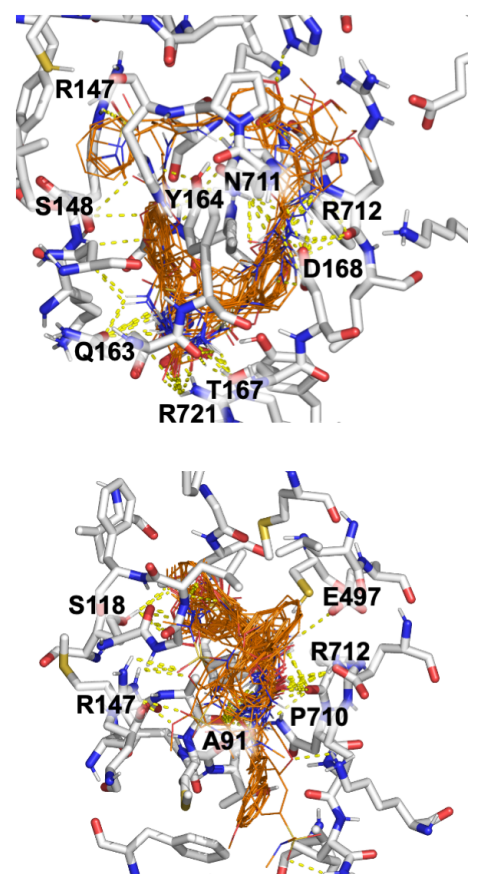

Figure S5. Models of OM analogues bound to the PPS and NR conformations. The ligands are represented as cyan (group1), blue (group 2) and orange (group 3) lines. The first 9 binding poses from Vina to the PPS (top row) and NR (bottom row) conformations are considered for each compound. Residues in the binding site are represented as sticks (carbon atoms in white), while polar contacts are shown as yellow dashed lines. Residues involved in recurring contacts are labelled. 


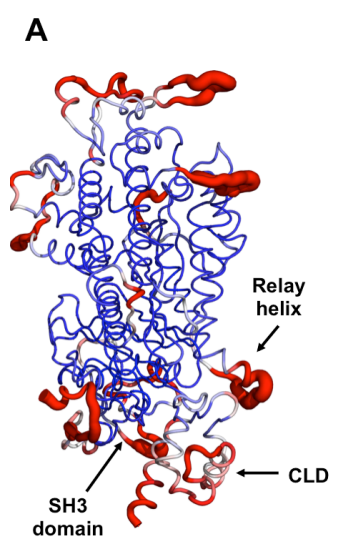

B

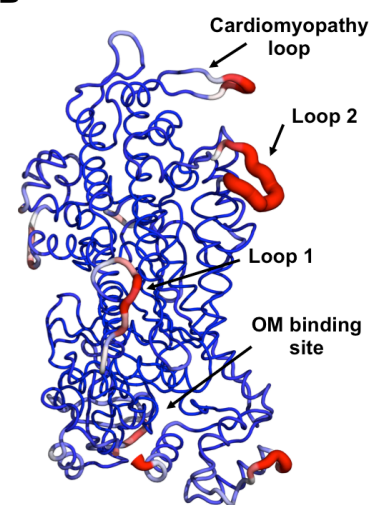

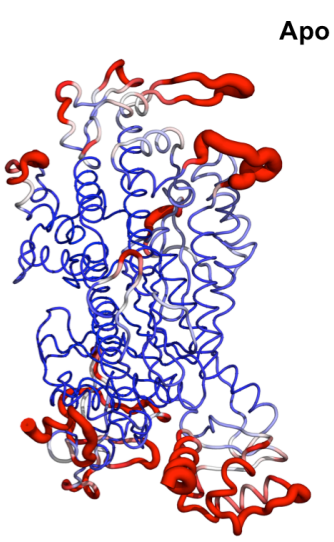

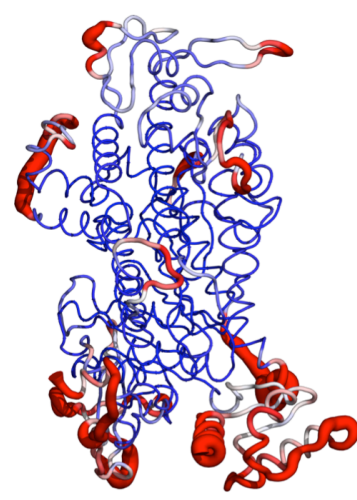

OM-bound
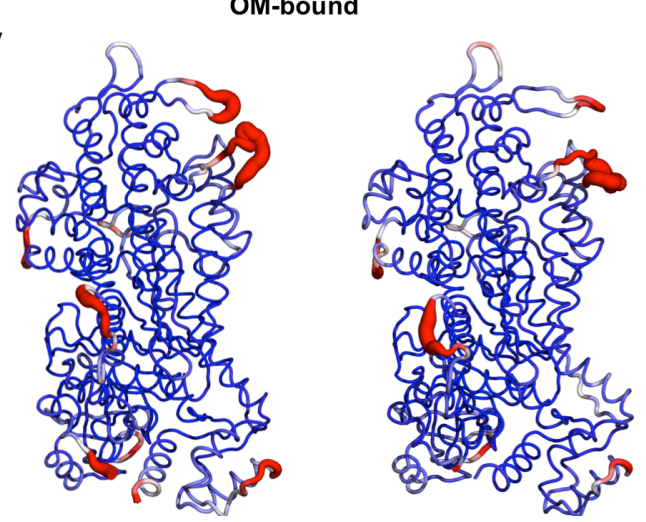
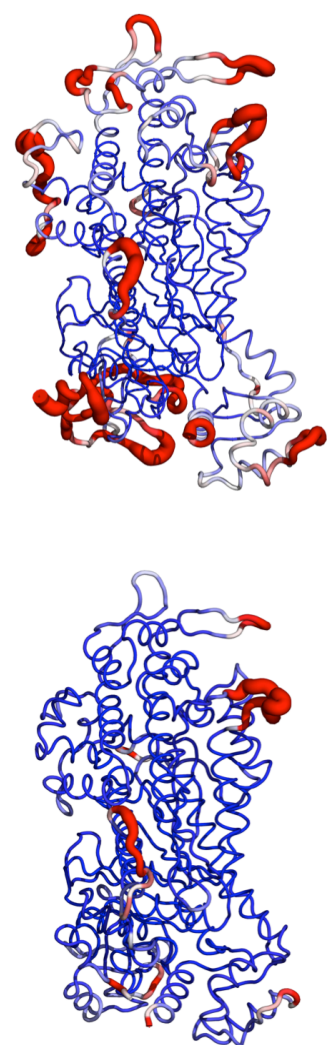

Figure S6. RMSF of the motor domain (PPS state) in Apo and OM-bound simulations. The RMSF is colour mapped onto the motor domain structure from blue $(0 \AA)$ to red $(3.4 \AA)$ for each Apo $(A)$ and OM-bound $(B)$ replica. The average structure is used for each simulation. The thickness of the tube representation is proportional to the RMSF value. High flexibility regions and the OM binding site are also labelled. 


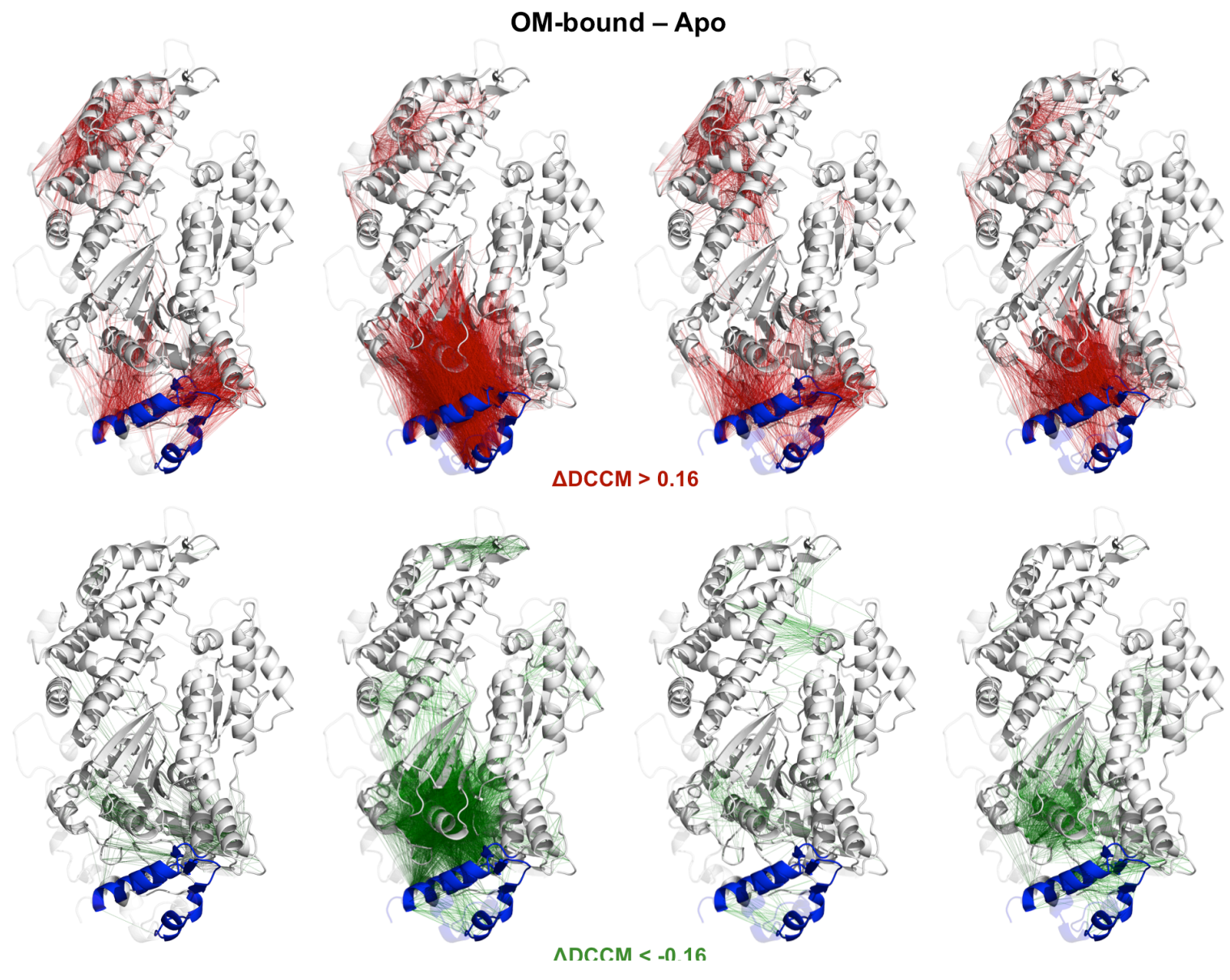

Figure S7. Comparison of dynamic cross-correlation networks of OM-bound and Apo simulations of the PPS state. Difference DCCM matrices ( $\triangle \mathrm{DCCM})$ calculated between pairs of OM-bound and Apo simulations are mapped onto the initial OM-bound structure. Edges connect residue pairs that have a positive (red) and a negative (green) $\triangle \mathrm{DCCM}$ value, using a threshold of 0.16 . The CLD domain is highlighted in blue. Highly flexible unstructured regions were excluded from the calculation (see Methods) 

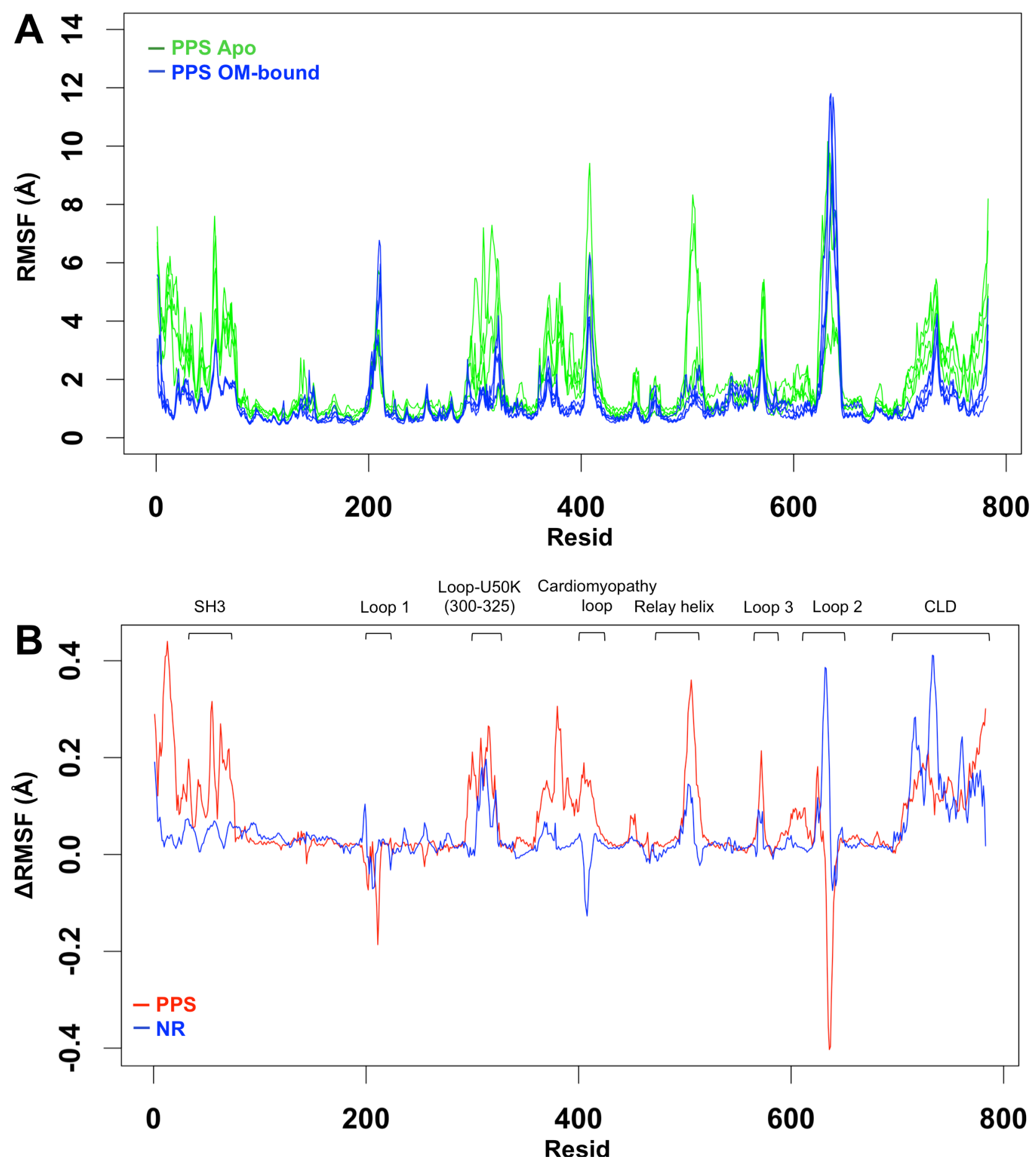

Figure S8. Comparison of RMSF profiles. (A) Profiles of RMSF values for PPS Apo (green) and OM-bound (blue) simulations. All replicas are reported. RMSF values were calculated on $C^{\alpha}$ atoms considering only the production part of the trajectories. (B) Difference between average Apo and OM-bound RMSF profiles calculated for PPS (red) and NR (blue) simulations. Positive values indicate residues with higher average flexibility in Apo simulations compared to OMbound ones. 

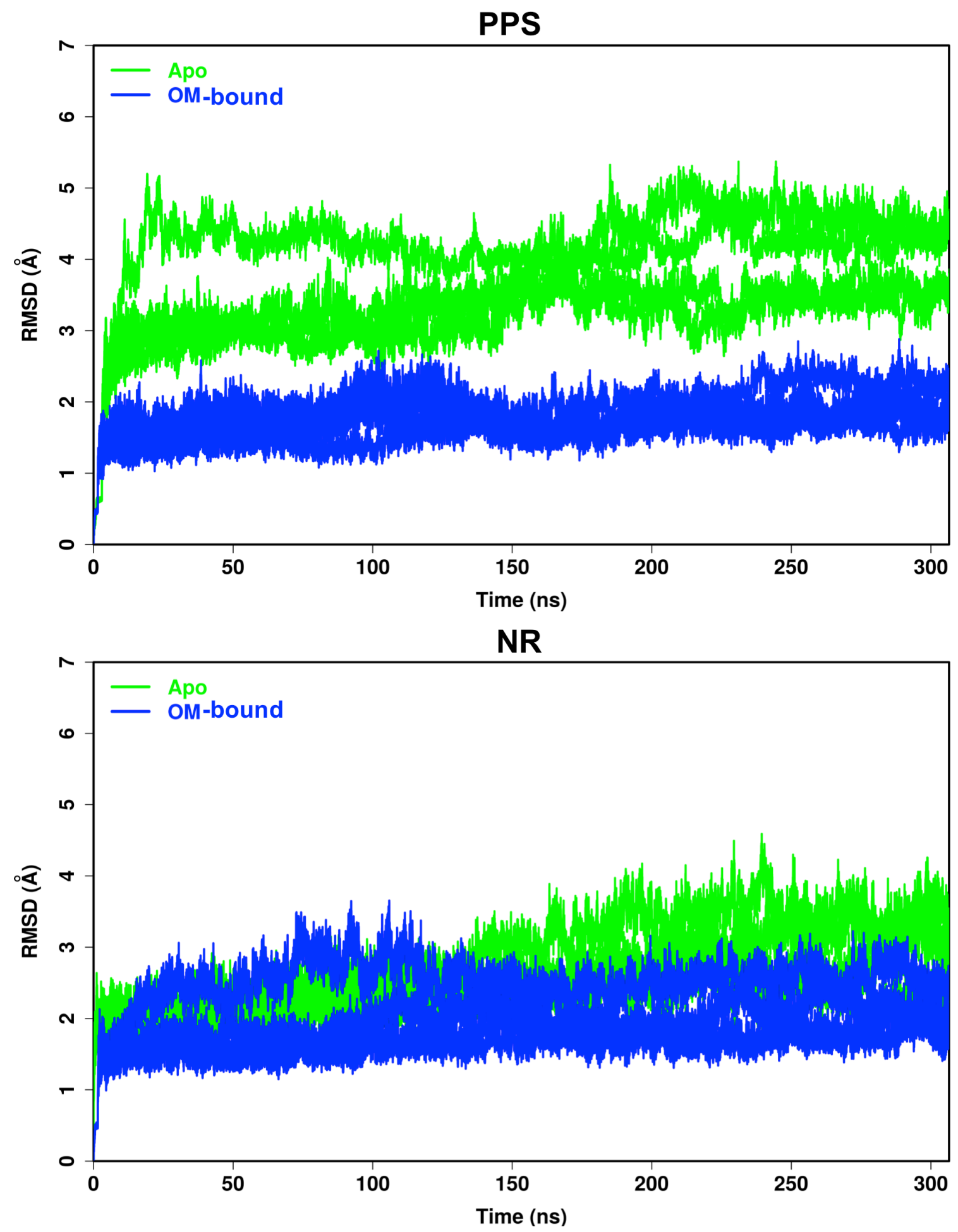

Figure S9. Time evolution of RMSD in PPS and NR simulations. The time evolution of RMSD values is reported for each replica of OM-bound (blue) and Apo (green) simulations of the PPS (A) and NR (state). Highly flexible unstructured regions were excluded from the calculation (see Methods). 

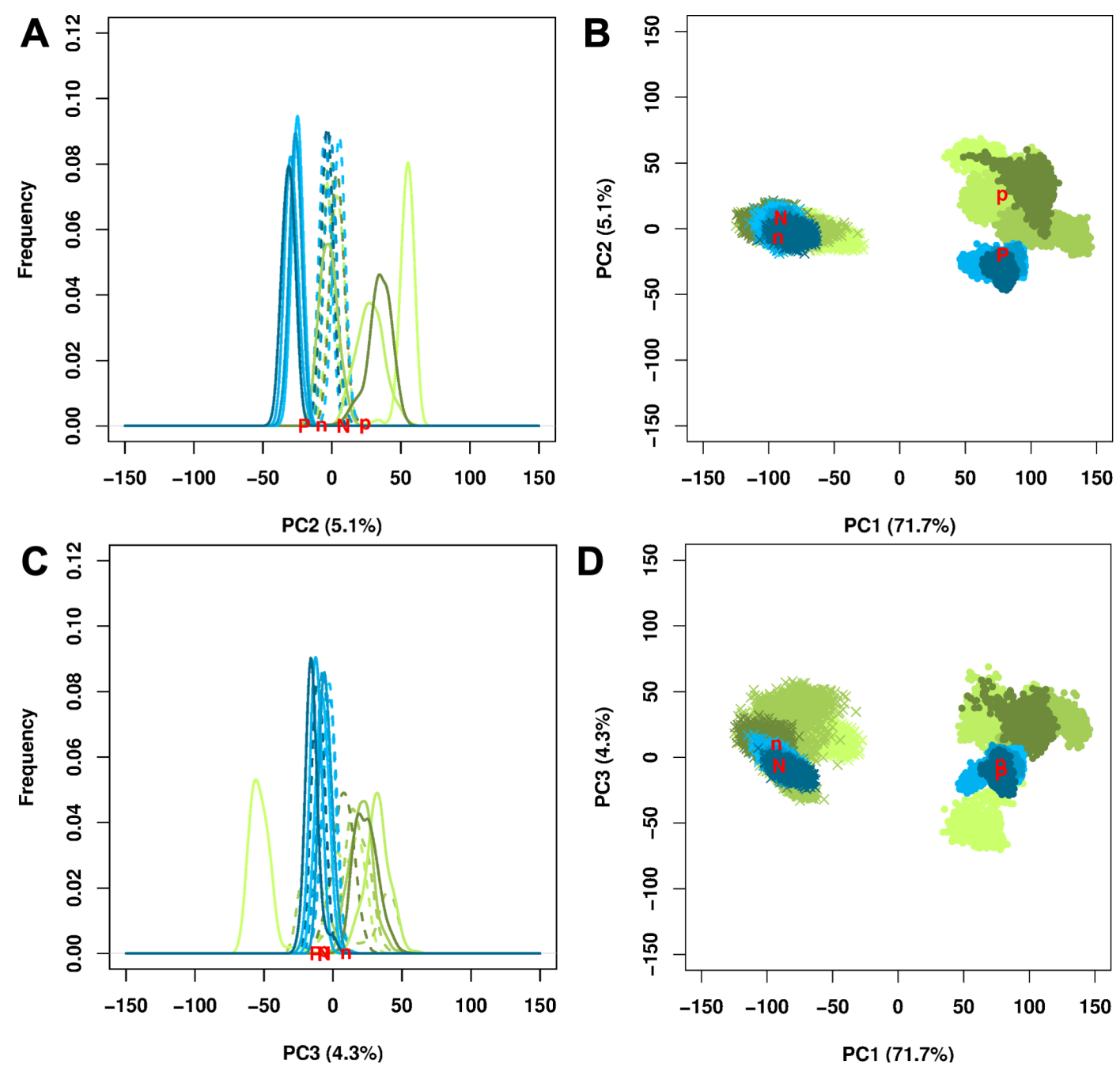

Figure S10. Principal component analysis of PPS and NR trajectories (Apo and OM-bound states). A/C. Distribution of projections of PPS (solid lines) and NR (dashed lines) trajectories on PC2 (A) and PC3 (C). B/D. PPS (dots) and NR (crosses) trajectories of the Apo (green shades) and OM-bound (blue shades) simulations are projected onto PC1 ( $x$ axis) and PC2 (B) or PC 3 (D) ( $y$ axis). The position of initial structures is indicated with letters ( $n=A p o N R, N=$ OM-bound NR, $p=$ Apo PPS, P = OM-bound PPS). PCs are calculated on the pseudo-trajectory obtained by concatenating all the 16 trajectories together. Highly flexible unstructured regions were excluded from the calculation (see Methods). The contribution of each PC to the total variance is reported in the axis label. 
A

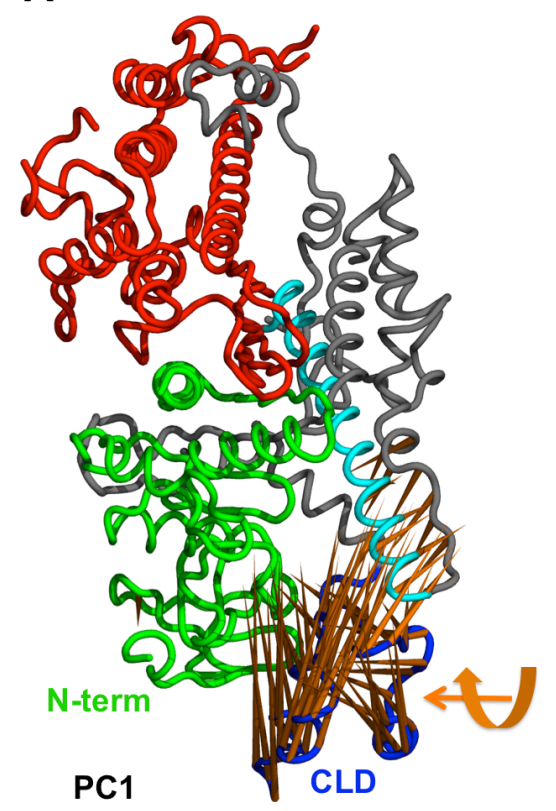

B

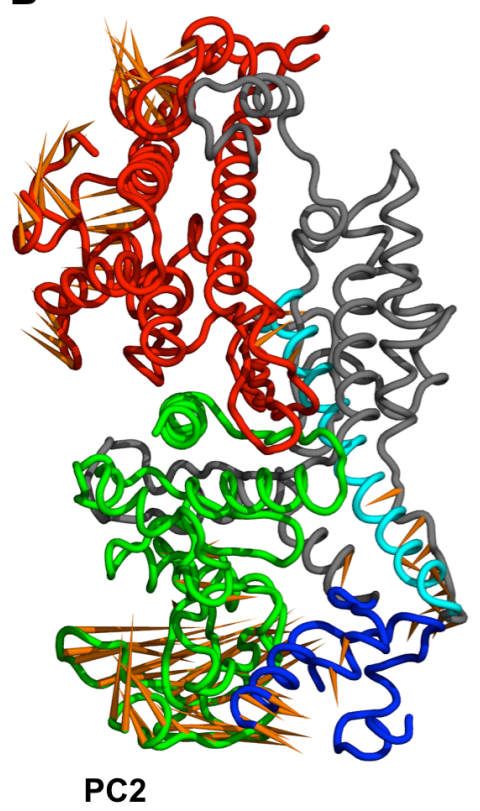

C

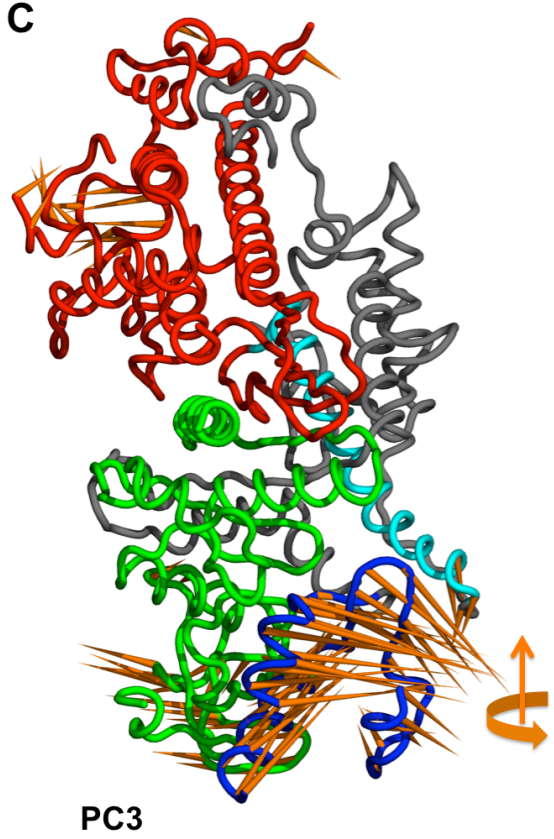

Figure S11. First three Principal Components of the concatenated pseudo-trajectory (PPS and NR, Apo and OM-bound states). In the porcupine representation, the orange spikes show the direction and relative amplitude of motion of each residue along the PC. Spikes shorter than $20 \%$ of the maximum length are not shown. Highly flexible unstructured regions were excluded from the calculation (see Methods). 
A

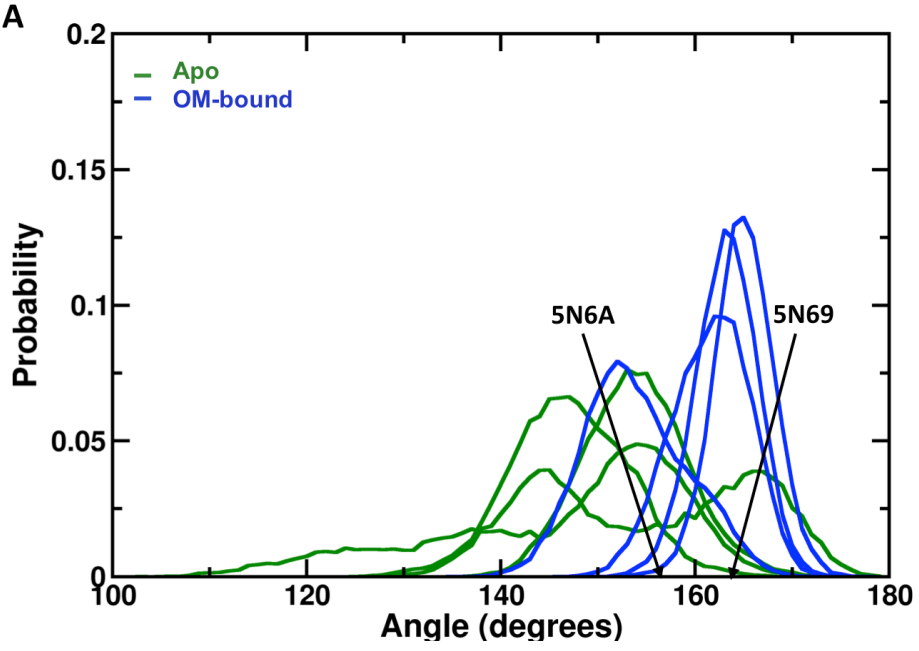

B

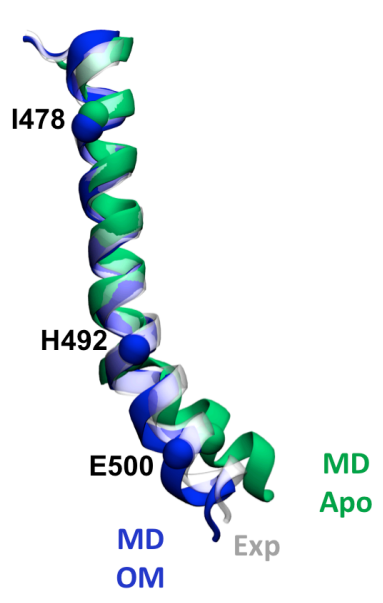

Figure S12. Bending of the relay helix during the MD simulations of the PPS state. The relay helix bending was measured by calculating the angle formed by residues 1478, H492 and E500 (C $\alpha$ atoms only). A. Probability distribution of the angle values observed during Apo (green) and OM-bound (blue) simulations. Arrows indicate the value of the angle measured for representative experimental structures of the pre-power stroke state (PDB IDs shown). $B$.

Representative structures from PPS Apo (green) and OM-bound (blue) simulations. The energyminimised experimental structure (PDB ID: 5 N69) is shown as transparent white cartoon. 
K146

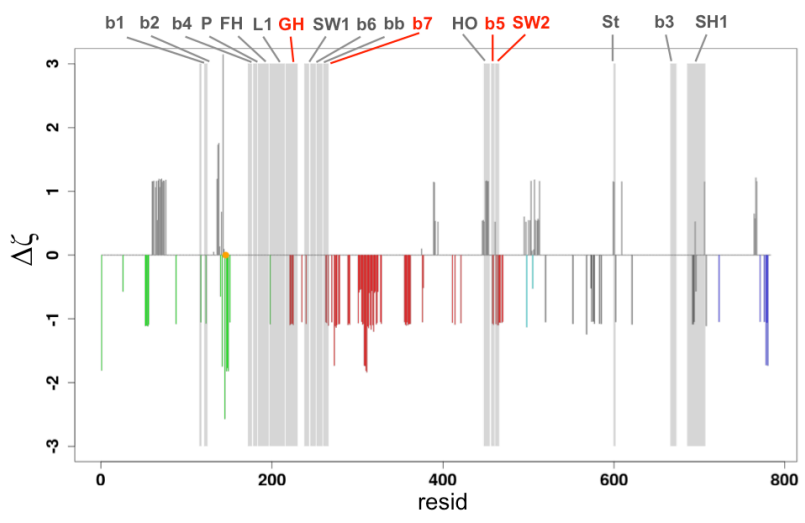

H666

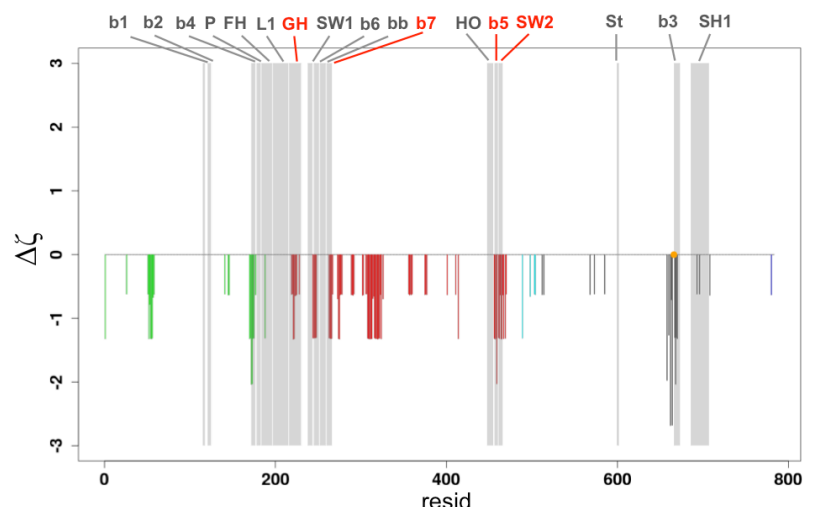

D168

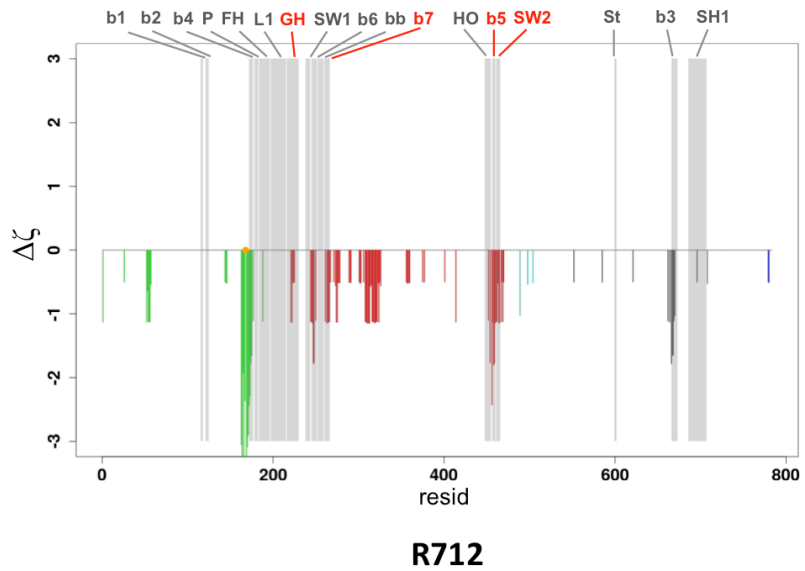

b1 b2 b4 P FH L1 GH SW1 b6 bb b7 HO b5 SW2 $\quad$ St $\quad$ b3 3 SH1

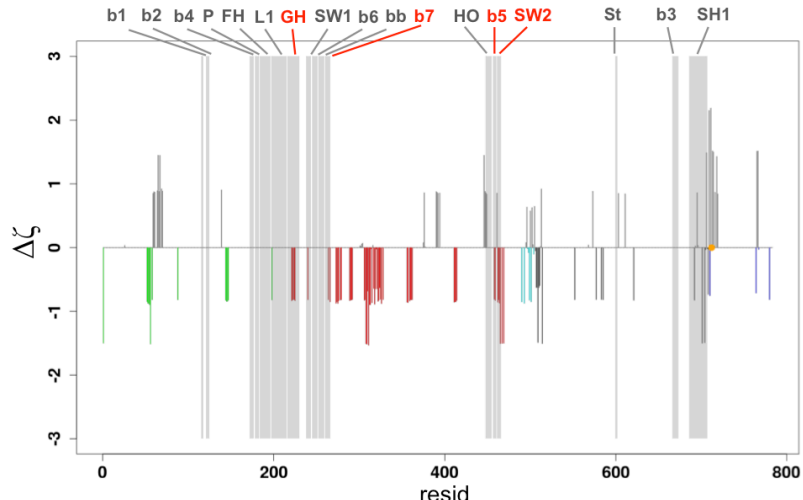

Figure S13. Profiles of $\Delta \zeta$ scores calculated for fragments in the OM-binding site. Plots of the difference between $\mathrm{OM}$ and Apo preferential connection scores $(\Delta \zeta)$, calculated using fragments in the OM binding site as source sites. Similar profiles were observed when using source fragments close to each other, so that plots are shown only for selected fragments representative of the different profile types, namely K146, D168, H666 and R712 (orange dots). A negative value indicates a stronger preferential connection to the source fragment in OMbound simulations compared to Apo ones. Negative bars are coloured according to their subdomain. Grey areas highlight the position of functional regions, namely the seven strands of the central $\beta$-sheet (b1 to b7), the P-loop (P), the F helix (FH), Loop $1(\mathrm{~L} 1)$, the G helix $(\mathrm{GH})$, Switch 1 (SW1), the $\beta$-bulge (bb), the OH loop $(\mathrm{OH})$, Switch 2 (SW2), the Strut (St) and the SH1 helix $(\mathrm{SH} 1)$. 

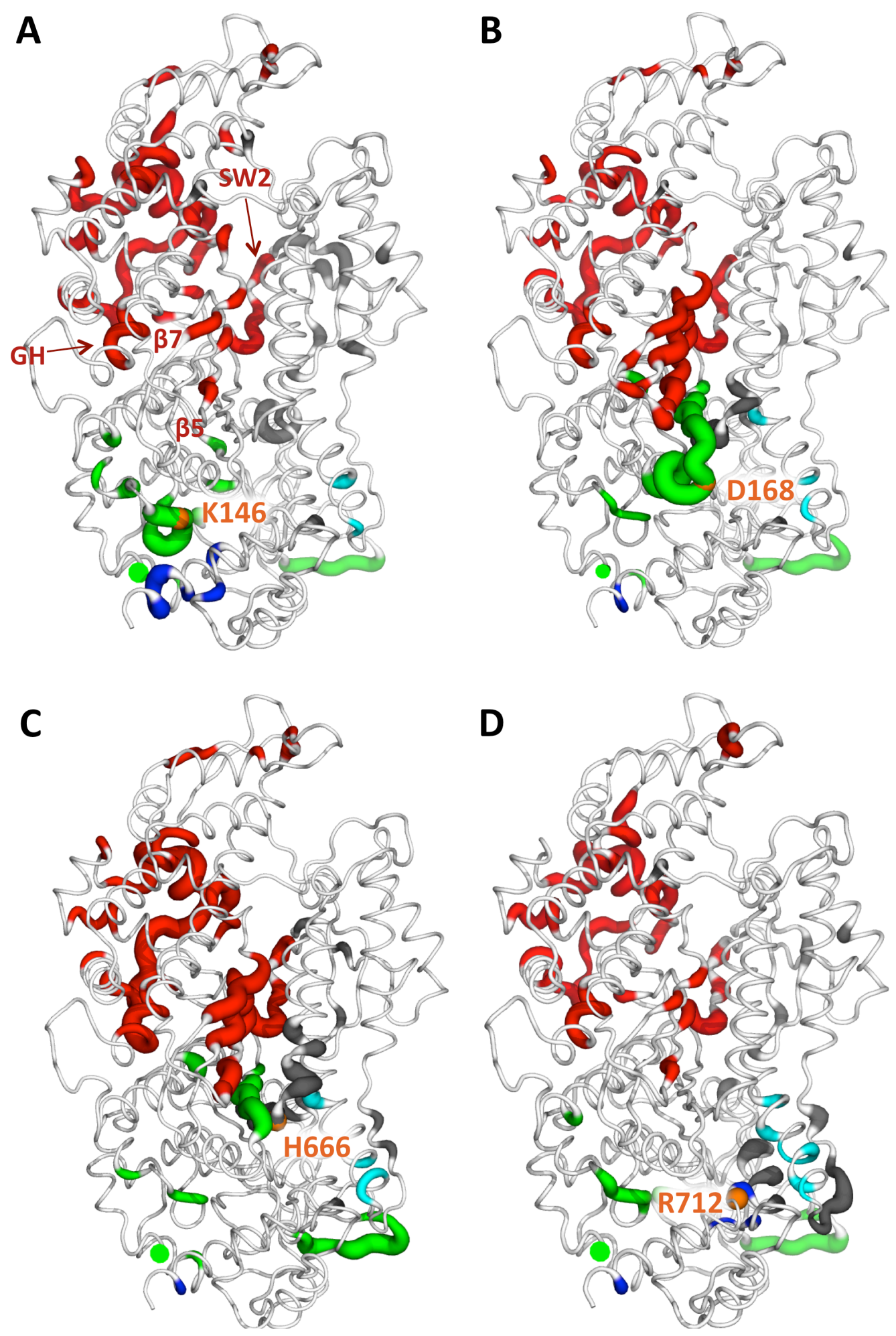

Figure S14. Mapping of $\Delta \zeta$ scores calculated for fragments in the OM-binding site.

Regions with negative values are coloured according to their sub-domain. The thickness of the tube is proportional to the magnitude of $\Delta \zeta$ values. Mapping is shown for K146 (A), D168 (B), H666 (C) and R712 (D). The position of the source fragment is indicated with an orange sphere. Highly flexible unstructured regions were excluded from the calculation (see Methods) 

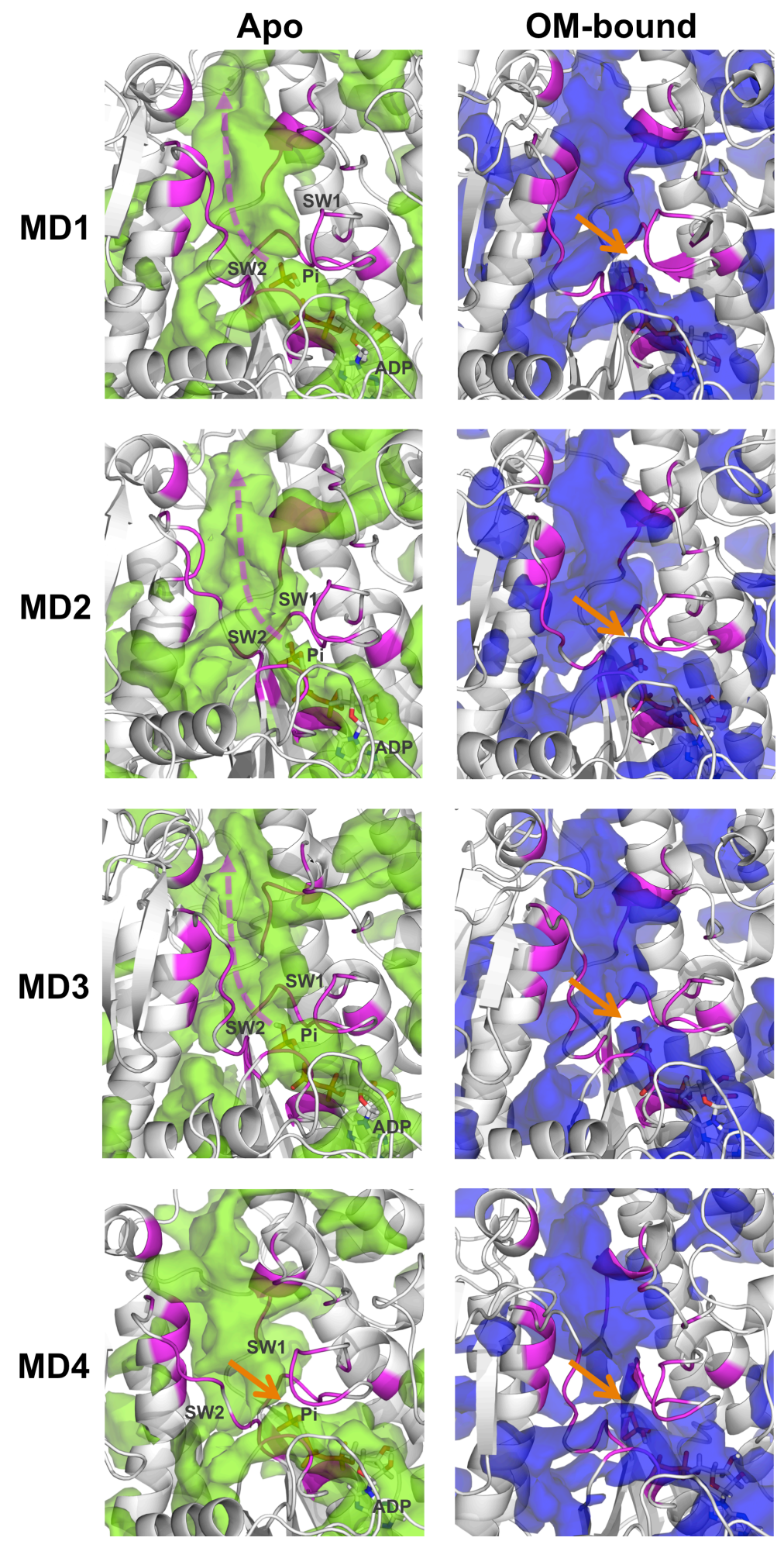

Figure S15. Pocket analysis in the nucleotide binding site. Pocket frequency maps calculated with MDpocket are represented as green (PPS Apo) and blue (PPS OM-bound) isosurfaces connecting points with frequency $=0.3$ for each replica. The discontinuity between the Pi-containing pocket and the backdoor I channel observed in the OM-bound simulations and in Apo MD4 is indicated with an orange arrow. The position of the residues lining the inner and outer backdoor I tube is indicated in magenta, while the approximate position of the tube is indicated as a dashed magenta arrow in Apo MD1-3. 

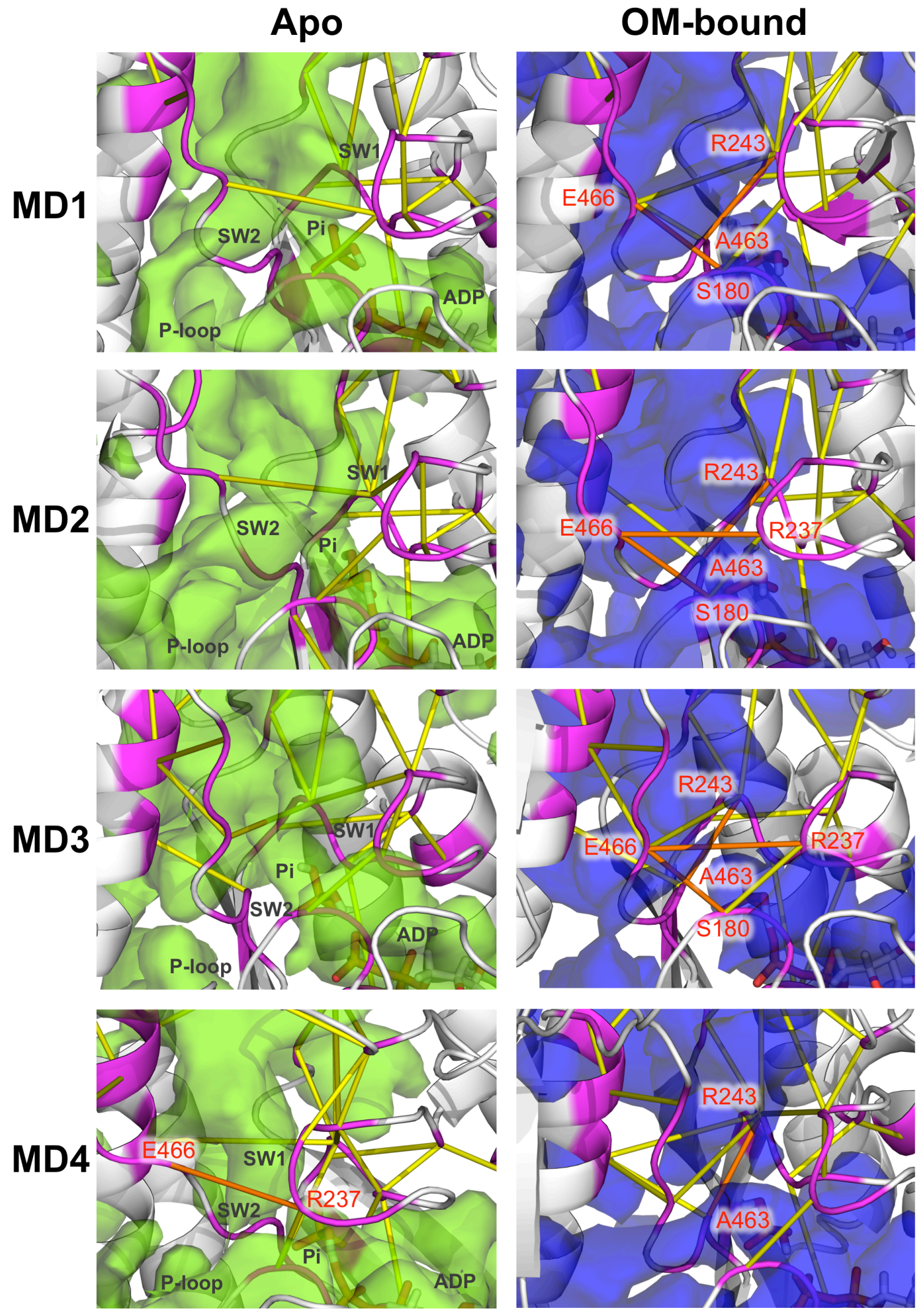

Figure S16. Inter-residue contacts in the backdoor I region. Backdoor I residues that are in contact (distance $<4 \AA$ ) for at least $50 \%$ of the trajectory are connected by an edge. Pocket frequency maps calculated with MDpocket are represented as green (PPS Apo) and blue (PPS OM-bound) isosurfaces connecting points with frequency $=0.3$. The position of the residues lining the inner and outer backdoor I tube is indicated in magenta in the cartoon representation. The narrower backdoor I tubes observed in OM-bound simulations seem to be correlated with the presence of S180-E466, R243-A463 and R237-E466 contacts (orange edges). 